Article

\title{
Interaction between Coffee Drinking and TRIB1 rs17321515 Single Nucleotide Polymorphism on Coronary Heart Disease in a Taiwanese Population
}

\author{
Yin-Tso Liu ${ }^{1,2}$, Disline Manli Tantoh ${ }^{3,4}{ }^{\text {, Lee Wang }}{ }^{4}$, Oswald Ndi Nfor ${ }^{4}$, Shu-Yi Hsu ${ }^{4}$, \\ Chien-Chang Ho ${ }^{5,6}\left(\mathbb{0}\right.$, Chia-Chi Lung ${ }^{4}$, Horng-Rong Chang ${ }^{7,8, *}$ and Yung-Po Liaw ${ }^{3,4, *}$
}

1 Institute of Medicine, Chung Shan Medical University, Taichung City 40201, Taiwan; cvsliu0325@gmail.com

2 Department of Cardiovascular Surgery, Asia University Hospital, Taichung 41354, Taiwan

3 Department of Medical Imaging, Chung Shan Medical University Hospital, Taichung City 40201, Taiwan; tantohdisline@gmail.com

4 Department of Public Health and Institute of Public Health, Chung Shan Medical University,

Taichung 40201, Taiwan; wl@csmu.edu.tw (L.W.); nforoswald22@gmail.com (O.N.N.); sui0209@gmail.com (S.-Y.H.); dinoljc@csmu.edu.tw (C.-C.L.)

5 Department of Physical Education, Fu Jen Catholic University, New Taipei 24205, Taiwan; ccho1980@gmail.com

6 Research and Development Center for Physical Education, Health, and Information Technology,

Fu Jen Catholic University, New Taipei 24205, Taiwan

7 Division of Nephrology, Department of Internal Medicine, Chung Shan Medical University Hospital, Taichung 40201, Taiwan

8 School of Medicine, Chung Shan Medical University, Taichung 40201, Taiwan

* Correspondence: chrcsmu@gmail.com (H.-R.C.); Liawyp@csmu.edu.tw (Y.-P.L.); Tel.: +886-424730022 (ext. 11838) (Y.-P.L.); Fax: +886-423248179 (Y.-P.L.)

Received: 5 March 2020; Accepted: 27 April 2020; Published: 2 May 2020

\begin{abstract}
A complex interplay of several genetic and lifestyle factors influence coronary heart disease (CHD). We determined the interaction between coffee consumption and the tribbles pseudokinase 1 (TRIB1) rs17321515 variant on coronary heart disease (CHD). Data on CHD were obtained from the National Health Insurance Research Database (NHIRD) while genotype data were collected from the Taiwan Biobank (TWB) Database. From the linked electronic health record data, 1116 individuals were identified with CHD while 7853 were control individuals. Coffee consumption was associated with a lower risk of CHD. The multivariate-adjusted odds ratio (OR) and 95\% confidence interval (CI) was $0.84(0.72-0.99)$. Association of CHD with the TRIB1 rs17321515 variant was not significant. The OR (95\% CI) was 1.01 (0.72-0.99). There was an interaction between TRIB1 rs17321515 and coffee consumption on CHD risk ( $p$ for interaction $=0.0330$ ). After stratification by rs17321515 genotypes, coffee drinking remained significantly associated with a lower risk of CHD only among participants with GG genotype (OR, $0.62 ; 95 \% \mathrm{CI}, 0.45-0.85)$. In conclusion, consumption of coffee was significantly associated with a decreased risk of CHD among Taiwanese adults with the TRIB1 GG genotype.
\end{abstract}

Keywords: coffee drinking; TRIB1; rs17321515; CHD; Taiwan Biobank

\section{Introduction}

Coronary heart disease, also known as ischemic heart disease (IHD) or coronary artery disease (CAD) is the top cause of global mortality [1,2]. It remains the second leading cause of death in Taiwan [3]. The global coronary heart disease (CHD) mortality is projected to grow from 7.594 million in 2016 to about 9.245 million in 2030 [4]. 
A complex interplay of numerous genetic and lifestyle factors influence the onset of CHD [5-7]. Genotypes are nonmodifiable factors, so they cannot be confounded by other factors. As such, they are capable of playing direct causal roles in disease development $[8,9]$. Identification of genetic variants associated with diseases and the underlying pathophysiological mechanisms is an important step in the development of potential drug targets [8].

Genetic predisposition accounts for about $30 \%-60 \%$ of CHD [10,11]. Despite this, most underlying genes and molecular pathways are yet to be fully explored and therefore a significant portion of CHD heritability is not clearly understood [2]. For instance, SNPs account for just a minute fraction (approximately $10-15 \%$ ) of CHD heritability $[1,2,5,12,13]$. The TRIB1 is among the top genes having genome-wide significant single nucleotide polymorphisms (SNPs) for CHD [14]. It is located on chromosome 8q24 and is greatly involved in cholesterol metabolism and atherosclerosis process [15]. One of its variants, rs17321515, has been associated with variations in plasma lipid levels and CHD [14,16-18].

Coffee is a popular beverage that is widely consumed in the world [19]. In Taiwan, coffee consumption has grown rapidly in recent years. So far, the local coffee industry has expanded significantly [20]. Several studies have investigated the effects of coffee consumption on CHD. However, results have been controversial. For instance, in one of the studies, excessive consumption was significantly associated with a moderate increase in the risk of CHD [21]. However, in another study, CHD risk was higher among moderate than for excessive coffee consumers [22]. Cardioprotective effects of coffee may stem from its richness in bioactive compounds like polyphenols that possess hypocholesterolemic, antihypertensive, anti-inflammatory, and antioxidant properties [23,24]. The antioxidant content in coffee was found to be higher than that in tea, vegetables, and fruits [25].

It is well known that interactions between genes and the environment influence disease outcomes [26]. So far, there is substantial information on genetic variation and dietary patterns (including but not limited to coffee consumption) and the risk of CHD. Results from a previous study indicated that a variant in the cytochrome P450 1A2 gene (CYP1A2) modifies the association between caffeinated coffee consumption and the risk of myocardial infection [27]. Nevertheless, pinpointing a specific polymorphic variant is challenging considering that individual differences may exist in response to coffee or caffeine. To our knowledge, no prior study has discussed specific genotypes that can modify the association between coffee intake and the risk of CHD in Taiwan. In light of this, we determined the interaction between coffee consumption and the TRIB1 rs17321515 variant on CHD.

\section{Materials and Methods}

\subsection{Data Source and Participants}

We used electronic data of Taiwan Biobank (TWB) participants recruited between 2008 and 2015. Participants provided blood samples for DNA extraction and completed questionnaires covering a wide range of medical, social, and lifestyle information. All participants provided informed consent. Genotyping was done using the Axiom ${ }^{\mathrm{TM}}$ Genome-Wide TWB 2.0 Array plate (Santa Clara, CA, USA). Data on CHD between 1998 and 2015 were obtained from the National Health Insurance Research Database (NHIRD). The TWB database was linked to the NHIRD using encrypted personal identification numbers. This study was approved by the Institutional Review Board of Chung Shan Medical University (CS2-16114).

In total, 9001 biobank participants were recruited. After excluding persons with incomplete questionnaires $(n=13)$ and genotype information $(n=19), 1116$ coronary heart disease patients and 7853 controls were included in the study.

\subsection{Assessment of Variables}

Coronary heart disease was identified based on either two outpatient visits or one admission with reported International Classification of Diseases, Ninth Revision, Clinical Modification (ICD-9-CM) 
code 410-414. Participants were classified as regular coffee drinkers if they drank coffee at least three days per week in the last 6 months. Details of the covariates and physical measures used in the text have been described in our recent publication [28].

\subsection{Selection of the Polymorphic Variant}

The rs17321515 variant in the TRIB1 gene was selected based on the literature search. This variant was selected because of its previous associations with CHD and dyslipidemia, especially in Han Chinese populations $[16,17]$. We also searched Google Scholar and selected rs762551 variant in the CYP1A2 gene which has been associated with caffeine metabolism and increased risk of myocardial infarction. We followed a standard quality control procedure and excluded SNPs with (1) a low call rate $(<95 \%)$, (2) $p$-value of $<1.0 \times 10^{-3}$ for the Hardy-Weinberg equilibrium test, and (3) minor allele frequency of $<0.05$. Moreover, we removed one individual from the pair of related samples based on pairwise identity-by-descent (IBD).

\subsection{Statistical Analysis}

We used the statistical analysis system (SAS) software (version 9.4, SAS Institute, Cary, NC, USA) and PLINK (v1.09, http://pngu.mgh.harvard.edu/purcell/plink/) to perform analyses. Differences between groups were compared using the chi-square test. Associations of coffee and the rs17321515 variant with CHD were determined using logistic regression analysis. Adjusted variables included sex, age, educational level, smoking, alcohol intake, tea consumption, vegetarian diet, body mass index (BMI), diabetes, hypertension, hyperlipidemia, atrial fibrillation, and CYP1A2 rs762551 variant. Odds ratios with their $95 \%$ confidence intervals were estimated.

\section{Results}

The descriptive data of 1116 participants with CHD and 7863 control individuals are shown in Table 1. Significant differences existed between patients and controls for coffee drinking, sex, age, educational level, cigarette smoking, exercise, body mass index (BMI), diabetes, hypertension, hyperlipidemia, atrial fibrillation, and vegetarian diet $(p<0.05)$. However, there were no significant differences between patients and controls for the TRIB1 rs17321515 and CYP1A2 rs762551 genotypes, alcohol, and tea consumption. Differences in coffee consumption habits between men and women as well as between those in different age groups are shown in Table 2. 
Table 1. Descriptive data of the study participants.

\begin{tabular}{|c|c|c|c|}
\hline \multirow{2}{*}{ Variable } & Controls $(n=7853)$ & CHD Patients ( $n=1116)$ & \multirow{2}{*}{$p$-Value } \\
\hline & $n(\%)$ & $n(\%)$ & \\
\hline Coffee drinking & & & $<0.0001$ \\
\hline No & $5269(67.10)$ & $824(73.84)$ & \\
\hline Yes & $2584(32.90)$ & $292(26.16)$ & \\
\hline TRIB1 rs17321515 & & & 0.9920 \\
\hline GG & $2362(30.08)$ & $335(30.02)$ & \\
\hline $\mathrm{GA}+\mathrm{AA}$ & $5491(69.92)$ & $781(69.98)$ & \\
\hline CYP1A2 rs762551 & & & 0.1490 \\
\hline AA & $3326(42.35)$ & $500(44.80)$ & \\
\hline $\mathrm{AC}+\mathrm{CC}$ & $4527(57.65)$ & $616(55.20)$ & \\
\hline Sex & & & $<0.0001$ \\
\hline Women & $4275(54.44)$ & $520(46.59)$ & \\
\hline Men & $3578(45.56)$ & $596(53.41)$ & \\
\hline Age (years) & & & $<0.0001$ \\
\hline $30-39$ & $2042(26.00)$ & $46(4.12)$ & \\
\hline $40-49$ & $2337(29.76)$ & $111(9.95)$ & \\
\hline $50-59$ & $2217(28.23)$ & $415(37.19)$ & \\
\hline $60-70$ & $1257(16.01)$ & $544(48.75)$ & \\
\hline
\end{tabular}


Table 1. Cont.

\begin{tabular}{|c|c|c|c|}
\hline \multirow{2}{*}{ Variable } & Controls $(n=7853)$ & CHD Patients $(n=1116)$ & \multirow{2}{*}{$p$-Value } \\
\hline & $n(\%)$ & $n(\%)$ & \\
\hline Educational level & & & $<0.0001$ \\
\hline Elementary school & $493(6.28)$ & $170(15.23)$ & \\
\hline Junior and senior high school & $3258(41.49)$ & $498(44.62)$ & \\
\hline University and above & $4102(52.23)$ & $448(40.14)$ & \\
\hline Cigarette smoking & & & 0.0060 \\
\hline No & $6117(77.89)$ & $828(74.19)$ & \\
\hline Yes & $1736(22.11)$ & $288(25.81)$ & \\
\hline Alcohol drinking & & & 0.3540 \\
\hline No & $7031(89.53)$ & $989(88.62)$ & \\
\hline Yes & $822(10.47)$ & $127(11.38)$ & \\
\hline Exercise & & & $<0.0001$ \\
\hline No & $4702(59.88)$ & $474(42.47)$ & \\
\hline Yes & $3151(40.12)$ & $642(57.53)$ & \\
\hline BMI $\left(\mathrm{kg} / \mathrm{m}^{2}\right)$ & & & $<0.0001$ \\
\hline BMI < 18.5 (Underweight) & $215(2.74)$ & $11(0.99)$ & \\
\hline $\begin{array}{c}18.5 \leq \text { BMI }<24 \text { (Normal } \\
\text { weight) }\end{array}$ & $3870(49.28)$ & $396(35.48)$ & \\
\hline $24 \leq \mathrm{BMI}<27$ (Overweight) & $2283(29.07)$ & $415(37.19)$ & \\
\hline BMI $\geq 27$ (Obesity) & $1485(18.91)$ & $294(26.34)$ & \\
\hline Diabetes & & & $<0.0001$ \\
\hline No & $6943(88.41)$ & $738(66.13)$ & \\
\hline Yes & $910(11.59)$ & $378(33.87)$ & \\
\hline Hypertension & & & $<0.0001$ \\
\hline No & $6424(81.80)$ & $391(35.04)$ & \\
\hline Yes & $1429(18.20)$ & $725(64.96)$ & \\
\hline Hyperlipidemia & & & $<0.0001$ \\
\hline No & $5828(74.21)$ & $372(33.33)$ & \\
\hline Yes & 2025 (25.79) & $744(66.67)$ & \\
\hline Atrial fibrillation & & & $<0.0001$ \\
\hline No & 7833 (99.75) & 1089 (97.58) & \\
\hline Yes & $20(0.25)$ & $27(2.42)$ & \\
\hline Tea consumption & & & 0.1110 \\
\hline No & $4894(62.30)$ & $723(64.78)$ & \\
\hline Yes & $2959(37.68)$ & $393(35.22)$ & \\
\hline Vegetarian diet & & & 0.0090 \\
\hline No & 7011 (89.28) & 1025 (91.85) & \\
\hline Yes & 842 (10.72) & $91(8.15)$ & \\
\hline
\end{tabular}

CHD: Coronary heart disease, BMI: Body mass index, TRIB1: tribbles pseudokinase 1; CYP1A2: cytochrome P450 1A2. GG, GA, and AA represent genotypes in the TRIB1 rs17321515 variant while AA, AC, and CC represent genotypes in the CYP1A2 rs762551 variant. 
Table 2. Characteristics of study participants based on coffee consumption.

\begin{tabular}{|c|c|c|c|c|c|c|c|c|c|}
\hline & \multicolumn{4}{|c|}{ No Coffee Drinking } & \multicolumn{4}{|c|}{ Coffee Drinking } & \multirow{3}{*}{$p$-Value } \\
\hline & \multicolumn{2}{|c|}{ Controls } & \multicolumn{2}{|c|}{ CHD Patients } & \multicolumn{2}{|c|}{ Controls } & \multicolumn{2}{|c|}{ CHD Patients } & \\
\hline & $n$ & $\%$ & $n$ & $\%$ & $n$ & $\%$ & $n$ & $\%$ & \\
\hline TRIB1 rs17321515 & & & & & & & & & 0.4130 \\
\hline GG & 1574 & 29.87 & 261 & 31.67 & 788 & 30.50 & 74 & 25.34 & \\
\hline GA & 2564 & 48.66 & 396 & 48.06 & 1272 & 49.23 & 148 & 50.68 & \\
\hline $\mathrm{AA}$ & 1131 & 21.47 & 167 & 20.27 & 524 & 20.28 & 70 & 23.97 & \\
\hline CYP1A2 rs762551 & & & & & & & & & 0.5160 \\
\hline $\mathrm{AA}$ & 2229 & 42.30 & 361 & 43.81 & 1097 & 42.45 & 139 & 47.60 & \\
\hline $\mathrm{AC}$ & 2411 & 45.76 & 375 & 45.51 & 1176 & 45.51 & 126 & 43.15 & \\
\hline $\mathrm{CC}$ & 629 & 11.94 & 88 & 10.68 & 311 & 12.04 & 27 & 9.25 & \\
\hline Sex & & & & & & & & & $<0.0001$ \\
\hline Women & 2785 & 52.86 & 391 & 47.45 & 1490 & 57.66 & 129 & 44.18 & \\
\hline Men & 2484 & 47.14 & 433 & 52.55 & 1094 & 42.34 & 163 & 55.82 & \\
\hline Age & & & & & & & & & $<0.0001$ \\
\hline $30-39$ & 1340 & 25.43 & 31 & 3.76 & 702 & 27.17 & 15 & 5.14 & \\
\hline $40-49$ & 1485 & 28.18 & 77 & 9.34 & 852 & 32.97 & 34 & 11.64 & \\
\hline $50-59$ & 1521 & 28.87 & 310 & 37.62 & 696 & 26.93 & 105 & 35.96 & \\
\hline $60-70$ & 923 & 17.52 & 406 & 49.27 & 334 & 12.93 & 138 & 47.26 & \\
\hline Education & & & & & & & & & $<0.0001$ \\
\hline Elementary school & 379 & 7.19 & 143 & 17.35 & 114 & 4.41 & 27 & 9.25 & \\
\hline Junior and Senior high school & 2259 & 42.87 & 375 & 45.51 & 999 & 38.66 & 123 & 42.12 & \\
\hline University and above & 2631 & 49.93 & 306 & 37.14 & 1471 & 56.93 & 142 & 48.63 & \\
\hline Cigarette smoking & & & & & & & & & $<0.0001$ \\
\hline No & 4174 & 79.22 & 628 & 76.21 & 1943 & 75.19 & 200 & 68.49 & \\
\hline Yes & 1095 & 20.78 & 196 & 23.79 & 641 & 24.81 & 92 & 31.51 & \\
\hline Alcohol drinking & & & & & & & & & 0.1890 \\
\hline No & 4734 & 89.85 & 737 & 89.44 & 2297 & 88.89 & 252 & 86.30 & \\
\hline Yes & 535 & 10.15 & 87 & 10.56 & 287 & 11.11 & 40 & 13.70 & \\
\hline Physical activity & & & & & & & & & $<0.0001$ \\
\hline No & 3142 & 59.63 & 353 & 42.84 & 1560 & 60.37 & 121 & 41.44 & \\
\hline Yes & 2127 & 40.37 & 471 & 57.16 & 1024 & 39.63 & 171 & 58.56 & \\
\hline BMI $\left(\mathrm{kg} / \mathrm{m}^{2}\right)$ & & & & & & & & & $<0.0001$ \\
\hline BMI $<18.5$ & 156 & 2.96 & 9 & 1.09 & 59 & 2.28 & 2 & 0.68 & \\
\hline $18.5 \leq \mathrm{BMI}<24$ & 2629 & 49.90 & 308 & 37.38 & 1241 & 48.03 & 88 & 30.14 & \\
\hline $24 \leq \mathrm{BMI}<27$ & 1491 & 28.30 & 294 & 35.68 & 792 & 30.65 & 121 & 41.44 & \\
\hline $\mathrm{BMI} \geq 27$ & 993 & 18.85 & 213 & 25.85 & 492 & 19.04 & 81 & 27.74 & \\
\hline Diabetes & & & & & & & & & $<0.0001$ \\
\hline No & 4631 & 87.89 & 538 & 65.29 & 2312 & 89.47 & 200 & 68.49 & \\
\hline Yes & 638 & 12.11 & 286 & 34.71 & 272 & 10.53 & 92 & 31.51 & \\
\hline Hypertension & & & & & & & & & $<0.0001$ \\
\hline No & 4237 & 80.41 & 280 & 33.98 & 2187 & 84.64 & 111 & 38.01 & \\
\hline Yes & 1032 & 19.59 & 544 & 66.02 & 397 & 15.36 & 181 & 61.99 & \\
\hline Hyperlipidemia & & & & & & & & & $<0.0001$ \\
\hline No & 3873 & 73.51 & 285 & 34.59 & 1955 & 75.66 & 87 & 29.79 & \\
\hline Yes & 1396 & 26.49 & 539 & 65.41 & 629 & 24.34 & 205 & 70.21 & \\
\hline Atrial fibrillation & & & & & & & & & $<0.0001$ \\
\hline No & 5255 & 99.73 & 804 & 97.57 & 2578 & 99.77 & 285 & 97.60 & \\
\hline Yes & 14 & 0.27 & 20 & 2.43 & 6 & 0.23 & 7 & 2.40 & \\
\hline Tea consumption & & & & & & & & & $<0.0001$ \\
\hline No & 3518 & 66.77 & 571 & 69.3 & 1376 & 53.25 & 152 & 52.05 & \\
\hline Yes & 1751 & 33.23 & 253 & 30.7 & 1208 & 46.75 & 140 & 47.95 & \\
\hline Vegetarian diet & & & & & & & & & $<0.0001$ \\
\hline No & 4646 & 88.18 & 761 & 92.35 & 2365 & 91.52 & 264 & 90.41 & \\
\hline Yes & 623 & 11.82 & 63 & 7.65 & 219 & 8.48 & 28 & 9.59 & \\
\hline
\end{tabular}

CHD: Coronary heart disease, BMI: Body mass index, TRIB1: tribbles pseudokinase 1, CYP1A2: cytochrome P450 1 A2.

Coffee drinking was associated with a lower risk of CHD (OR, 0.84; 95\% CI, 0.72-0.99), as shown in Table 3. Association with the TRIB1 rs17321515 variant was not significant; the OR was 1.01, $95 \% \mathrm{CI}=0.87-1.18$. However, for the CYP1A2 rs762551 variant, the OR was 0.86 with a $95 \% \mathrm{CI}$ of 0.74-0.99 for AC+CC, compared to the AA genotype. Corresponding ORs (95\% CI) for CHD 
were 1.53 (1.07-2.19) for ages 40-49 years, 3.92 (2.82-5.46) for ages 50-59 years, 6.46 (4.59-9.09) for ages 60-70 years, 1.23 (1.04-1.46) for overweight, 1.35 (1.11-1.63) for obesity, 1.19 (1.01-1.41) for diabetes, 3.40 (2.91-3.98) for hypertension, 2.25 (1.91-2.63) for hyperlipidemia, and 4.09 (2.14-7.82) for atrial fibrillation.

Table 3. Association of CHD with associated variables.

\begin{tabular}{|c|c|c|}
\hline Variable & OR & $95 \% \mathrm{CI}$ \\
\hline \multicolumn{3}{|l|}{ Coffee drinking (ref: No) } \\
\hline Yes & 0.84 & $0.72-0.99$ \\
\hline \multicolumn{3}{|l|}{ TRIB1 rs17321515 (ref: GG) } \\
\hline $\mathrm{GA}+\mathrm{AA}$ & 1.01 & $0.87-1.18$ \\
\hline \multicolumn{3}{|l|}{ CYP1A2 rs762551 (ref: AA) } \\
\hline $\mathrm{AC}+\mathrm{CC}$ & 0.86 & $0.74-0.99$ \\
\hline \multicolumn{3}{|l|}{ Sex (ref: Women) } \\
\hline Men & 1.17 & $0.98-1.39$ \\
\hline \multicolumn{3}{|l|}{ Age (ref: 30-39) } \\
\hline $40-49$ & 1.53 & $1.07-2.19$ \\
\hline $50-59$ & 3.92 & $2.82-5.46$ \\
\hline $60-70$ & 6.46 & $4.59-9.09$ \\
\hline \multicolumn{3}{|c|}{ Educational level (ref: Elementary school) } \\
\hline Junior and senior high school & 0.97 & $0.77-1.21$ \\
\hline University and above & 1.01 & $0.80-1.28$ \\
\hline \multicolumn{3}{|l|}{ Cigarette smoking (ref: No) } \\
\hline Yes & 1.07 & $0.88-1.30$ \\
\hline \multicolumn{3}{|l|}{ Alcohol drinking (ref: No) } \\
\hline Yes & 0.79 & $0.62-1.01$ \\
\hline \multicolumn{3}{|l|}{ Exercise (ref: No) } \\
\hline Yes & 1.07 & $0.92-1.24$ \\
\hline \multicolumn{3}{|l|}{ BMI (ref: $18.5 \leq$ BMI < 24) } \\
\hline $\mathrm{BMI}<18.5$ & 0.78 & $0.40-1.51$ \\
\hline $24 \leq \mathrm{BMI}<27$ & 1.23 & $1.04-1.46$ \\
\hline $\mathrm{BMI} \geq 27$ & 1.35 & $1.11-1.63$ \\
\hline \multicolumn{3}{|l|}{ Diabetes (ref: No) } \\
\hline Yes & 1.19 & $1.01-1.41$ \\
\hline \multicolumn{3}{|l|}{ Hypertension (ref: No) } \\
\hline Yes & 3.40 & $2.91-3.98$ \\
\hline \multicolumn{3}{|l|}{ Hyperlipidemia (ref: No) } \\
\hline Yes & 2.25 & $1.91-2.63$ \\
\hline \multicolumn{3}{|l|}{ Atrial fibrillation (ref: No) } \\
\hline Yes & 4.09 & $2.14-7.82$ \\
\hline \multicolumn{3}{|l|}{ Tea consumption (ref: No) } \\
\hline Yes & 0.97 & $0.83-1.13$ \\
\hline \multicolumn{3}{|l|}{ Vegetarian diet (ref: No) } \\
\hline Yes & 0.96 & $0.75-1.24$ \\
\hline
\end{tabular}

Ref: reference, CHD: Coronary heart disease, BMI: Body mass index, OR: odds ratio, CI: confidence interval, TRIB1: tribbles pseudokinase 1, CYP1A2: cytochrome P450 1A2.

There was a significant interaction $(p=0.0330)$ between TRIB1 rs17321515 and coffee drinking on CHD risk (Table 4). After stratification by rs17321515 genotypes, coffee drinking remained significantly associated with a lower risk of CHD only among those with the GG genotype (OR, 0.62; 95\% CI, 0.45-0.85). There was no interaction between the CYP1A2 rs762551 variant and coffee consumption. 
Table 4. Association of CHD with coffee drinking stratified by rs17321515 genotypes.

\begin{tabular}{|c|c|c|c|c|}
\hline \multirow{2}{*}{ Variable } & \multicolumn{2}{|c|}{ TRIB1 rs17321515 (GG) } & \multicolumn{2}{|c|}{ TRIB1 rs17321515 (GA+AA) } \\
\hline & OR & $95 \% \mathrm{CI}$ & OR & $95 \%$ CI \\
\hline \multicolumn{5}{|l|}{ Coffee drinking (ref: No) } \\
\hline Yes & 0.62 & $0.45-0.85$ & 0.95 & $0.79-1.15$ \\
\hline \multicolumn{5}{|l|}{ CYP1A2 rs762551 (ref: AA) } \\
\hline $\mathrm{AC}+\mathrm{CC}$ & 0.83 & $0.64-1.08$ & 0.86 & $0.72-1.02$ \\
\hline \multicolumn{5}{|l|}{ Sex (ref: Women) } \\
\hline Men & 1.26 & $0.91-1.74$ & 1.13 & $0.92-1.38$ \\
\hline \multicolumn{5}{|l|}{ Age (ref: 30-39) } \\
\hline $40-49$ & 0.79 & $0.41-1.54$ & 2.01 & $1.30-3.10$ \\
\hline $50-59$ & 3.46 & $1.96-6.12$ & 4.21 & $2.79-6.35$ \\
\hline $60-70$ & 5.52 & $3.05-10.00$ & 7.10 & $4.66-10.84$ \\
\hline \multicolumn{5}{|c|}{ Educational level (ref: Elementary school) } \\
\hline Junior and senior high school & 1.16 & $0.76-1.77$ & 0.91 & $0.69-1.18$ \\
\hline University and above & 1.22 & $0.78-1.89$ & 0.94 & $0.71-1.25$ \\
\hline \multicolumn{5}{|l|}{ Cigarette smoking (ref: No) } \\
\hline Yes & 0.90 & $0.63-1.30$ & 1.15 & $0.91-1.45$ \\
\hline \multicolumn{5}{|l|}{ Alcohol drinking (ref: No) } \\
\hline Yes & 0.74 & $0.47-1.17$ & 0.81 & $0.61-1.08$ \\
\hline \multicolumn{5}{|l|}{ Exercise (ref: No) } \\
\hline Yes & 1.04 & $0.79-1.36$ & 1.08 & $0.90-1.29$ \\
\hline \multicolumn{5}{|l|}{ BMI (ref: $18.5 \leq$ BMI < 24) } \\
\hline $\mathrm{BMI}<18.5$ & 1.91 & $0.68-5.40$ & 0.51 & $0.21-1.21$ \\
\hline $24 \leq \mathrm{BMI}<27$ & 1.49 & $1.09-2.05$ & 1.15 & $0.94-1.40$ \\
\hline $\mathrm{BMI} \geq 27$ & 2.03 & $1.43-2.88$ & 1.14 & $0.90-1.43$ \\
\hline \multicolumn{5}{|l|}{ Diabetes (ref: No) } \\
\hline Yes & 1.12 & $0.82-1.53$ & 1.22 & $1.00-1.49$ \\
\hline \multicolumn{5}{|l|}{ Hypertension (ref: No) } \\
\hline Yes & 3.84 & $2.87-5.12$ & 3.28 & $2.72-3.96$ \\
\hline \multicolumn{5}{|l|}{ Hyperlipidemia (ref: No) } \\
\hline Yes & 1.94 & $1.44-2.60$ & 2.40 & $1.99-2.90$ \\
\hline \multicolumn{5}{|l|}{ Atrial fibrillation (ref: No) } \\
\hline Yes & 8.13 & $2.44-27.09$ & 3.10 & $1.42-6.77$ \\
\hline \multicolumn{5}{|l|}{ Tea consumption (ref: No) } \\
\hline Yes & 1.14 & $0.86-1.52$ & 0.91 & $0.75-1.09$ \\
\hline \multicolumn{5}{|l|}{ Vegetarian diet (ref: No) } \\
\hline Yes & 0.88 & $0.54-1.42$ & 0.99 & $0.74-1.33$ \\
\hline rs $17321515^{*}$ coffee & \multicolumn{4}{|c|}{$p=0.0330$} \\
\hline
\end{tabular}

Ref: reference, CHD: Coronary heart disease, BMI: Body mass index, OR: odds ratio, CI: confidence interval, TRIB1: tribbles pseudokinase 1, CYP1A2: cytochrome P450 1A2.

\section{Discussion}

In the current study, we determined whether an interactive association exists between coffee intake and the TRIB1 rs17321515 variant with the risk of CHD. Our findings offered unique evidence that coffee intake might have a protective effect on CHD. We also found that contrary to previous findings [17,29], rs17321515 was not associated with CHD. Importantly, we found evidence of an interaction between rs17321515 and coffee intake. After stratification by rs17321515 genotypes, we found that CHD risk was significantly lower among those with GG genotype who consumed coffee relative to their non-coffee-drinking counterparts. However, there was no association among those with the GA+AA genotype, indicating that the genotype may not have any effect on CHD. TRIB1 rs17321515 has been associated with a decreased risk of CAD among Europeans, Malays, and Asian Indians [15,30,31]. However, their analyses were not performed based on coffee intake.

So far, several studies have investigated the independent effects of coffee intake and TRIB1 rs17321515 on cardiovascular disease risk. Of the studies, those investigating coffee consumption and 
cardiovascular disease risk have shown conflicting results. Contrary to findings from case-control studies which suggested that coffee intake was detrimental to coronary arteries [32], umbrella reviews of observational and intervention studies have found it to be beneficial even in little amounts [33,34]. An increased risk of CHD previously reported among heavy coffee drinkers was attributed to smoking [35]. In light of this, we included smoking in our analysis.

Regarding the rs17321515 polymorphism, its AA+GA genotypes were previously associated with an increased risk of CHD among Han Chinese [36]. In a Singapore Malay Eye study of 3280 adults aged 40-79 years old, the odds ratio for CHD among carriers of this variant was 1.23 for each copy of the A allele [31]. Even though the rs17321515 variant has been assessed in Asian populations as noted above, attempts have not been made to replicate it in Taiwan. This was the motivation behind the selection of this variant for the current study.

As stated earlier, lifestyle changes and genetic factors play a substantial role in the development of cardiovascular diseases. Of note, the interactive associations of both factors with CHD have not been widely reported. When coffee intake and the TRIB1 rs17321515 variant were included in our model with adjustments for smoking and other lifestyle variables, we found that the GG genotype was significantly protective against CHD disease in individuals who consumed coffee compared to those who did not. The underlying mechanisms of interaction between coffee drinking and TRIB1 rs17321515 SNP on CHD are not completely understood. However, metabolites in coffee are believed to influence protective endogenous pathways by modulation of gene expression [37].

One of the main variables included in our model was the rs762551 variant in the CYP1A2 gene. We chose this variant based on its previous association with caffeine metabolism and its role in modifying the association between caffeinated coffee and the risk of heart disease [27]. Contrary to expectation, we found that $\mathrm{AC}+\mathrm{CC}$, compared to the AA genotype was protective against CHD in both the adjusted (OR, 0.86; 95\% CI (0.74-0.99) and the separate model (Supplementary Table S1). By performing stratified analyses, we found that associations of CYP1A2 rs762551 genotypes with CHD were not significant (Supplementary Table S2). Besides, there was no interaction between the variant and coffee consumption. Given that our findings are based on a limited number of coffee consumers, further investigations would be needed to clarify these associations.

In this study, we also observed that coffee consumption habits between cases and controls differed significantly based on gender and different age groups. However, differences in consumption based on gender and age are yet to be adequately determined, particularly in Taiwan.

We believe that these results will help to enhance the knowledge on the role of coffee in the association between rs17321515 variant and CHD among Taiwanese adults. However, the current study is just a first step to examine this association, which remains a fundamental issue for future research.

This study was limited in several ways. First, about $70 \%$ of the population studied did not consume any coffee. Such a limited number of coffee drinkers may preclude the possibility of observing meaningful associations between coffee and CHD. Next, our questionnaire did not have information on the type of coffee, caffeine content (that is, caffeinated or decaffeinated), methods of preparation, and the daily amount of consumption. We understand that these attributes may have different effects on CHD. Therefore, we recommend further research in this area. Second, well-established risk factors such as smoking, exercise, education, male sex, diabetes, tea-drinking, and vegetarian diet were not associated with the risk of CHD in the current population. This is an indication that our study population might not be representative of typical CHD study populations. Third, there is a possibility of nondifferential misclassification bias as information on coffee intake was based on self-report Lastly, even though the TWB is representative of the general population, only individuals who are 30-70 years old were recruited in the project. Therefore, we could not analyze data of adults under 30 or over 70 years of age. 


\section{Conclusions}

In conclusion, our findings highlight the interactive association of coffee drinking and TRIB1 rs17321515 polymorphism on coronary heart disease in Taiwanese adults. Taken together, we found that the risk of CHD was significantly lower among those with GG genotype who consumed coffee compared to their non-coffee-drinking counterparts. These results have provided considerable knowledge on gene-nutrient interaction in relation to cardiovascular disease.

Supplementary Materials: The following are available online at http:/www.mdpi.com/2072-6643/12/5/1301/s1. Table S1: Association of CHD with rs762551 variant and associated factors, Table S2: Association of CHD with coffee drinking stratified by rs762551 genotypes.

Author Contributions: Conceptualization, Y.-T.L., D.M.T., L.W., O.N.N., S.-Y.H., C.-C.H., C.-C.L., H.-R.C., and Y.-P.L.; formal analysis, S.-Y.H., C.-C.L., and Y.-P.L.; methodology, Y.-T.L., D.M.T., L.W., O.N.N., S.-Y.H., C.-C.H., C.-C.L., H.-R.C., and Y.-P.L.; supervision, H.-R.C., and Y.-P.L.; writing-original draft, Y.-T.L., D.M.T., L.W., and O.N.N., writing-review and editing Y.-T.L., D.M.T., L.W., O.N.N., S.-Y.H., C.-C.H., C.-C.L., H.-R.C., and Y.-P.L. All authors have read and agreed to the published version of the manuscript.

Funding: The Ministry of Science and Technology (MOST), Taiwan partly funded this work (MOST 107-2627-M-040-002, 108-2621-M-040-00, and 107-EPA-F-017-002).

Acknowledgments: Authors would like to thank the Ministry of Science and Technology for the financial support.

Conflicts of Interest: The authors declare no conflict of interest.

\section{Abbreviations}

SNP: single nucleotide polymorphism, CHD: coronary heart disease, TWB: Taiwan Biobank, NHIRD: National Health Insurance Research Database, OR: odds ratio, CI: confidence interval, BMI: body mass index, ICD-9-CM: International Classification of Diseases, Ninth Revision, Clinical Modification.

\section{References}

1. Deloukas, P.; Kanoni, S.; Willenborg, C.; Farrall, M.; Assimes, T.L.; Thompson, J.R.; Ingelsson, E.; Saleheen, D.; Erdmann, J.; the CARDIoGRAMplusC4D Consortium; et al. Large-Scale association analysis identifies new risk loci for coronary artery disease. Nat. Genet. 2012, 45, 25-33. [CrossRef] [PubMed]

2. Mäkinen, V.-P.; Civelek, M.; Meng, Q.; Zhang, B.; Zhu, J.; Levian, C.; Huan, T.; Segrè, A.V.; Ghosh, S.; Vivar, J.; et al. Integrative genomics reveals novel molecular pathways and gene networks for coronary artery disease. PLoS Genet. 2014, 10, e1004502. [CrossRef]

3. Li, Y.-H.; Chen, J.-W.; Lin, T.-H.; Wang, Y.-C.; Wu, C.-C.; Yeh, H.-I.; Huang, C.-C.; Chang, K.-C.; Wu, C.-K.; Chen, P.-W.; et al. A performance guide for major risk factors control in patients with atherosclerotic cardiovascular disease in Taiwan. J. Formos. Med. Assoc. 2020, 119, 674-684. [CrossRef] [PubMed]

4. WHO. Projections of Mortality and Causes of Death, 2016 to 2060. Available online: https://www.who.int/ healthinfo/global_burden_disease/projections/en/ (accessed on 5 February 2019).

5. Said, M.A.; Van De Vegte, Y.; Zafar, M.; Van Der Ende, Y.; Raja, G.K.; Verweij, N.; Van Der Harst, P. Contributions of interactions between lifestyle and genetics on coronary artery disease risk. Curr. Cardiol. Rep. 2019, 21, 89. [CrossRef]

6. Said, M.A.; Verweij, N.; Van Der Harst, P. Associations of combined genetic and lifestyle risks with incident cardiovascular disease and diabetes in the UK Biobank study. JAMA Cardiol. 2018, 3, 693. [CrossRef]

7. Khera, A.V.; Emdin, C.A.; Drake, I.; Natarajan, P.; Bick, A.; Cook, N.R.; Chasman, D.I.; Baber, U.; Mehran, R.; Rader, D.J.; et al. Genetic risk, adherence to a healthy lifestyle, and coronary disease. N. Engl. J. Med. 2016, 375, 2349-2358. [CrossRef]

8. Kingsmore, S.F.; Lindquist, I.E.; Mudge, J.; Gessler, D.D.; Beavis, W.D. Genome-wide association studies: Progress and potential for drug discovery and development. Nat. Rev. Drug Discov. 2008, 7, 221-230. [CrossRef]

9. Stein, E.A.; Mellis, S.; Yancopoulos, G.D.; Stahl, N.; Logan, D.; Smith, W.B.; Lisbon, E.; Gutierrez, M.; Webb, C.; $\mathrm{Wu}, \mathrm{R}$; et al. Effect of a monoclonal antibody to PCSK9 on LDL cholesterol. N. Engl. J. Med. 2012, 366, 1108-1118. [CrossRef]

10. Peden, J.F.; Farrall, M. Thirty-five common variants for coronary artery disease: The fruits of much collaborative labour. Hum. Mol. Genet. 2011, 20, R198-R205. [CrossRef] 
11. Marenberg, M.E.; Risch, N.; Berkman, L.F.; Floderus, B.; De Faire, U. Genetic susceptibility to death from coronary heart disease in a study of twins. N. Engl. J. Med. 1994, 330, 1041-1046. [CrossRef]

12. Schunkert, H.; König, I.R.; Kathiresan, S.; Reilly, M.; Assimes, T.L.; Holm, H.; Preuss, M.; Stewart, A.F.; Barbalić, M.; Gieger, C.; et al. Large-scale association analysis identifies 13 new susceptibility loci for coronary artery disease. Nat. Genet. 2011, 43, 333-338. [CrossRef] [PubMed]

13. Clarke, R.; Peden, J.F.; Hopewell, J.C.; Kyriakou, T.; Goel, A.; Heath, S.; Parish, S.; Barlera, S.; Franzosi, M.G.; Rust, S.; et al. Genetic variants associated with Lp(a) Lipoprotein level and coronary disease. N. Engl. J. Med. 2009, 361, 2518-2528. [CrossRef]

14. The IBC 50K CAD consortium correction: Large-scale gene-centric analysis identifies novel variants for coronary artery disease. PLoS Genet. 2012, 8, 7. [CrossRef]

15. Aung, L.H.H.; Yin, R.-X.; Wu, D.-F.; Li, Q.; Yan, T.-T.; Wang, Y.-M.; Li, H.; Wei, D.-X.; Shi, Y.-L.; Dezhai, Y. Association of the TRIB1 tribbles homolog 1 gene rs17321515 A>G polymorphism and serum lipid levels in the Mulao and Han populations. Lipids Heal. Dis. 2011, 10, 230. [CrossRef] [PubMed]

16. Liu, Q.; Xue, F.; Meng, J.; Liu, S.-S.; Chen, L.-Z.; Gao, H.; Geng, N.; Jin, W.-W.; Xin, Y.-N.; Xuan, S.-Y. TRIB1 rs17321515 and rs2954029 gene polymorphisms increase the risk of non-alcoholic fatty liver disease in Chinese Han population. Lipids Heal. Dis. 2019, 18, 61. [CrossRef] [PubMed]

17. Wang, L.; Jing, J.; Fu, Q.; Tang, X.; Su, L.; Wu, S.; Li, G.; Zhou, L. Association study of genetic variants at newly identified lipid gene TRIB1 with coronary heart disease in Chinese Han population. Lipids Heal. Dis. 2015, 14, 46. [CrossRef] [PubMed]

18. Wang, J.; Ban, M.R.; Zou, G.Y.; Cao, H.; Lin, T.; Kennedy, B.A.; Anand, S.; Yusuf, S.; Huff, M.W.; Pollex, R.L.; et al. Polygenic determinants of severe hypertriglyceridemia. Hum. Mol. Genet. 2008, 17, 2894-2899. [CrossRef]

19. Loftfield, E.; Cornelis, M.C.; Caporaso, N.; Yu, K.; Sinha, R.; Freedman, N. Association of Coffee Drinking with Mortality by Genetic Variation in Caffeine Metabolism: Findings From the UK Biobank. JAMA Intern. Med. 2018, 178, 1086-1097. [CrossRef]

20. Wann, J.-W.; Kao, C.-Y.; Yang, Y.-C. Consumer Preferences of Locally Grown Specialty Crop: The Case of Taiwan Coffee. Sustainability 2018, 10, 2396. [CrossRef]

21. Zhou, A.; Hyppönen, E. Long-term coffee consumption, caffeine metabolism genetics, and risk of cardiovascular disease: A prospective analysis of up to 347,077 individuals and 8368 cases. Am. J. Clin. Nutr. 2019, 109, 509-516. [CrossRef]

22. Ding, M.; Bhupathiraju, S.; Satija, A. Long-term coffee consumption and risk of cardiovascular disease: A systematic review and a dose-response meta-analysis of prospective cohort studies. J. Vasc. Surg. 2014, 59, 1471. [CrossRef]

23. Larsson, S.C. Coffee, tea, and cocoa and risk of stroke. Stroke 2014, 45, 309-314. [CrossRef] [PubMed]

24. Butt, M.S.; Sultan, M.T. Coffee and its consumption: Benefits and risks. Crit. Rev. Food Sci. Nutr. 2011, 51, 363-373. [CrossRef] [PubMed]

25. Svilaas, A.; Sakhi, A.K.; Andersen, L.F.; Svilaas, T.; Ström, E.C.; Jacobs, D.R.; Ose, L.; Blomhoff, R. Intakes of antioxidants in coffee, wine, and vegetables are correlated with plasma carotenoids in humans. J. Nutr. 2004, 134, 562-567. [CrossRef] [PubMed]

26. Rappaport, S. Genetic factors are not the major causes of chronic diseases. PLoS ONE 2016, 11, e0154387. [CrossRef]

27. Cornelis, M.C.; El-Sohemy, A.; Kabagambe, E.; Campos, H. Coffee, CYP1A2 genotype, and risk of myocardial infarction. JAMA 2006, 295, 1135. [CrossRef]

28. Liu, Y.-T.; Nfor, O.N.; Wang, L.; Hsu, S.-Y.; Lung, C.-C.; Tantoh, D.M.; Wu, M.-C.; Chang, H.-R.; Liaw, Y.-P. Interaction between sex and LDLR rs688 polymorphism on hyperlipidemia among Taiwan Biobank adult participants. Biomolecules 2020, 10, 244. [CrossRef]

29. Willer, C.J.; Sanna, S.; Jackson, A.U.; Scuteri, A.; Bonnycastle, L.L.; Clarke, R.; Heath, S.; Timpson, N.J.; Najjar, S.S.; Stringham, H.M.; et al. Newly identified loci that influence lipid concentrations and risk of coronary artery disease. Nat. Genet. 2008, 40, 161-169. [CrossRef]

30. Teslovich, T.M.; Musunuru, K.; Smith, A.V.; Edmondson, A.C.; Stylianou, I.M.; Koseki, M.; Pirruccello, J.P.; Ripatti, S.; Chasman, D.I.; Willer, C.J.; et al. Biological, clinical and population relevance of 95 loci for blood lipids. Nature 2010, 466, 707-713. [CrossRef] 
31. Tai, E.S.; Sim, X.L.; Ong, T.H.; Wong, T.Y.; Saw, S.M.; Aung, T.; Kathiresan, S.; Orho-Melander, M.; Ordovas, J.M.; Tan, J.T.; et al. Polymorphisms at newly identified lipid-associated loci are associated with blood lipids and cardiovascular disease in an Asian Malay population. J. Lipid Res. 2008, 50, 514-520. [CrossRef]

32. Sofi, F.; Conti, A.A.; Gori, A.M.; Luisi, M.L.E.; Casini, A.; Abbate, R.; Gensini, G.F. Coffee consumption and risk of coronary heart disease: A meta-analysis. Nutr. Metab. Cardiovasc. Dis. 2007, 17, 209-223. [CrossRef] [PubMed]

33. Grosso, G.; Godos, J.; Galvano, F.; Giovannucci, E.L. Coffee, Caffeine, and Health Outcomes: An Umbrella Review. Annu. Rev. Nutr. 2017, 37, 131-156. [CrossRef] [PubMed]

34. Poole, R.; Kennedy, O.J.; Roderick, P.; Fallowfield, J.; Hayes, P.C.; Parkes, J. Coffee consumption and health: Umbrella review of meta-analyses of multiple health outcomes. BMJ 2017, 359, 5024-5042. [CrossRef] [PubMed]

35. Kleemola, P.; Jousilahti, P.; Pietinen, P. Coffee consumption and the risk of coronary heart disease and death. ACC Curr. J. Rev. 2001, 10, 25. [CrossRef]

36. Liu, Q.; Liu, S.-S.; Zhao, Z.-Z.; Zhao, B.-T.; Du, S.-X.; Jin, W.-W.; Xin, Y.-N. TRIB1 rs17321515 gene polymorphism increases the risk of coronary heart disease in general population and non-alcoholic fatty liver disease patients in Chinese Han population. Lipids Heal. Dis. 2019, 18, 165-169. [CrossRef]

37. Bøhn, S.K.; Ward, N.C.; Hodgson, J.M.; Croft, K.D. Effects of tea and coffee on cardiovascular disease risk. Food Funct. 2012, 3, 575. [CrossRef]

(C) 2020 by the authors. Licensee MDPI, Basel, Switzerland. This article is an open access article distributed under the terms and conditions of the Creative Commons Attribution (CC BY) license (http://creativecommons.org/licenses/by/4.0/). 